\title{
BERWIRAUSAHA DENGAN SEMANGAT KOLABORASI BERSAMA KURIR ONLINE PADA PELAKU UMKM DI WILAYAH RENI JAYA PAMULANG BARAT
}

\author{
${ }^{1}$ Mahnun Mas'adi, ${ }^{2 *}$ Aidil Amin Effendy, ${ }^{3}$ Ahmad Nurhadi, ${ }^{4}$ Widhi \\ Wicaksono, ${ }^{5}$ Heri Murtiyoko \\ Universitas Pamulang \\ Email : $\underline{2 a i d i 100967 @ u n p a m . a c . i d ~}$
}

Manuskrip: Nov -2020; Ditinjau: Des -2020; Diterima: Des -2020;

Online: Jan-2021; Diterbitkan: Jan-2021

\begin{abstract}
ABSTRAK
Usaha Mikro, Kecil dan Menengah (UMKM) lebih didominasi usaha makanan, minuman dan pakaian, itu artinya pengusaha tahu,tempe, soto dan ketoprak perlu membuat inovasi, kreatifitas dan diferensiasi dari produk yaitu mempunyai ciri khas berupa kualitas produk, kemudahan melakukan pembelian, serta kecepatan dalam pengantaran dari produk yang dipesan. Soto dan ketoprak adalah menu sarapan dan juga makan siang yang hampir selalu ada di setiap gedung perkantoran, perumahan dan juga daerah-daerah pusat kegiatan masyarakat.

Metode kegiatan yang digunakan adalah melalui kunjungan langsung ke lokasi usaha para pengusaha tempe, tahu, soto, ketoprak dan penjahit Reni Pamulang dengan memberikan pemahaman dan motivasi kolaborasi online, bimbingan konsultatif dalam memberikan kepercayaan diri bagi pengusaha, praktek dan simulasi cara dagang dengan menggunakan aplikasi.

Hasil pengabdian masyarakat yang diperoleh adalah bertambahnya strategi pemasaran baik secara konvensional dan secara online, bertambahnya wawasan akan keilmuan pemasaran, dari cerita cerita sukses pengusaha pengusaha sukses yang mulai dari nol, dan dapat menjalankan usaha dengan bekal ilmu dan wawasan mengenai kewirausahaan yang diberikan.
\end{abstract}

\section{Kata Kunci : UMKM, Pemasaran Online, Wirausaha}

\section{PENDAHULUAN}

Pengusaha tempe dan tahu merupakan sektor usaha yang sangat menjanjikan karena proses pembuatan dari tempe dan tahu ataupun soto dan ketoprak terbilang dapat dikerjakan oleh industri rumahan di berbagai daerah. Dengan jumlah pekerja yang tidak terlalu banyak bisnis dan usaha ini sangat menjanjikan. Usaha mikro tersebut dapat dikatakan merupakan pokok bisnis UKM yang sangat laris dipasaran saat ini. Mudah dalam melakukan penjualan karena tahu dan tempe merupakan makanan pokok di masyarakat, soto dan ketoprak adalah menu sarapan dan juga makan siang yang hampir selalu ada di setiap 
gedung perkantoran, perumahan dan juga daerah-daerah pusat kegiatan masyarakat.

Untuk memberdayakan pengusaha maka seluruh guru, dosen dan elemen masyarakat terus berkomitmen mendukung dan mengoptimalkan pengusaha ukm dalam memperkokoh ideologi bangsa serta membentengi dari bahaya ideologi transaksional. Pengusaha dapat menghadirkan perubahan bangsa, negara dan agama ke arah yang lebih baik. Saat seorang pengusaha dapat memanfaatkan waktunya dengan baik dan memiliki ide dalam mendirikan usaha, maka mereka akan lebih termotivasi untuk mengembangkannya. Karena pengusaha merupakan harapan bangsa dan Negara yang harus berperan lebih dalam mengembangkan usaha di tengah-tengah masyarakat, jangan sampai perusahaan besar yang dikelola oleh pihak asing yang terus mendominasi sehingga akan membuat masyarakat menengah ke bawah semakin tidak dapat mendirikan usaha.

Mendirikan dan menjalankan usaha atau UMKM (Usaha Mikro, kecil dan Menengah), menurut Effendy, A. A., et al. (2020), "Haruslah mempunyai bekal ilmu dan keterampilan berwirausaha agar usaha yang dijalankan dapat berjalan dengan baik dan menghasilkan laba yang optimal."

Oleh karena itu, "Kompetensi SDM dalam hal pengetahuan, keterampilan, serta keahlian manajerial harus dimiliki oleh pemilik UMKM dan juga setiap individu yang bekerja di UMKM" (Ardiana et al. 2010). Maka termasuk pengusaha yang sudah menjalankan usaha sekalipun pun perlu ilmu pengetahuan dan keterampilan yang diperlukan dalam mengasah kemampuan wirausahanya dengan mengikuti sebuah penyuluhan atau pelatihan.

Ciri-ciri tertentu dalam kegiatan belajar menurut Edi Suardi dalam (Syaiful Bahri Djamarah et al, 2014:39-41), diantaranya yaitu Belajar mengajar memiliki tujuan, yakni untuk membentuk anak didik dalam suatu perkembangan tertentu dan didesain untuk mencapai tujuan yang telah ditetapkan. Dalam penyuluhan ini salah satu upaya tersebut dengan membekali dan memberikan pemahaman mengenai pemberian motivasi yang bertujuan untuk dapat membentuk dan membangun pengusaha yang unggul di era serba digital.

Oleh karena itu, pengusaha harus dibuatkan terobosan dan kita perlu mempersiapkan pengusaha tempe, tahu, soto, ketoprak dan penjahit yang makin kompeten dan mempunyai daya saing tinggi di masyarakat agar dapat mengurangi jumlah pengangguran dan menjadikan semangat wirausaha menjadi primadona di masyarakat serta proyeksi jangka panjang dapat berkontribusi terhadap pembangunan perekonomian nasional. Salah satu upaya tersebut dengan membekali dan memberikan pemahaman mengenai sikap kewirausahaan (entrepreneurship) melalui penyuluhan dan workshop.

Dalam pengabdian kepada masyarakat (PKM) yang dilakukan oleh dosendosen UNPAM khsusnya dosen Manajemen Fakultas Ekonomi ini salah satu upaya dalam membekali dan memberikan ilmu pengetahuan berwirausaha ditengah era digitalisasi dan kolaborasi sehingga nantinya pengusaha tempe, tahu, soto, ketoprak dan penjahit, sebagai sasaran peserta pengabdian kepada masyarakat (PKM), dapat meningkatkan volume penjualan karena luasnya jarak antar dan 
promosi yang dimiliki. Tema PKM kali ini adalah"Berwirausaha dengan semangat kolaborasi bersama Kurir Online"

\section{METODE PELAKSANAAN KEGIATAN}

Metode kegiatan yang digunakan adalah melalui kunjungan langsung ke lokasi usaha para pengusaha tempe, tahu, soto, ketoprak dan penjahit Reni Pamulang dengan memberikan pemahaman dan motivasi kolaborasi online, bimbingan konsultatif dalam memberikan kepercayaan diri bagi pengusaha, praktek dan simulasi cara dagang dengan menggunakan aplikasi, adapun uruatan kegiatannya sebagai berikut:

Tahap pertama: Dosen pengabdi berkoordinasi dengan mahasiswa dan asosiasi pedagang kecil di wilayah Pamulang Barat untuk mendapatkan perizinan dalam menyelenggarakan program pengabdian kepada masyarakat sebagai salah satu tugas dosen dalam mengamalkan tri dharma perguruan tinggi.

Tahap kedua: Dosen pengabdi melakukan pembinaan dengan memberikan penyuluhan, simulasi, diskusi dan tanya jawab mengenai pemasaran melalui media online kepada para pelaku UMKM yaitu para pedagang tempe, tahu, soto, dan ketoprak di Reni Jaya Pamulang Barat.

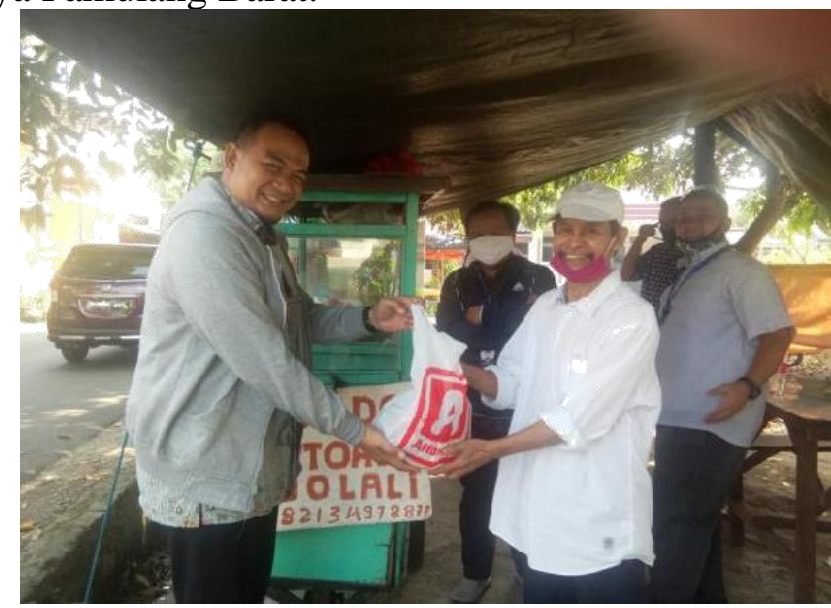

Gambar 1. Penyerahan Bantuan Pada Pelaku UMKM

Tahap terakhir: Dosen pengabdi mengadakan evaluasi atas kegiatan yang telah dilakukan

Selain memberikan penyuluhan dan simulasi, Dosen Pengabdi juga memberikan sembako kepada para pedagang sebagai bentuk solidaritas di masa Pandemi Covid-19 ini.

Kegiatan diadakan di sekitar wilayah kelurahan Pamulang Barat kepada para pelaku UMKM seperti Pengusaha tempe, tahu, soto, ketoprak dan Penjahit pakaian selama 3 hari yaitu pada tanggal 12 - 14 Juni 2020. 


\section{HASIL DAN PEMBAHASAN}

Pelatihan dan penyuluhan yang dilakukan tim Pengabdian dosen dan mahasiswa Unpam bertujuan untuk memberikan akses pemasaran secara online bagi para pelaku UMKM seperti pedagang tempe, tahu, soto, ketoprak dan penjahit di sekitar wilayah Reni Pamulang Barat yang masih melakukan kegiatan usahanya secara konvensional agar mampu bertahan dan bersaing di era globalisasi dan pandemi saat ini.

Hasil dari pemberian pelatihan dan penyuluhan oleh dosen Manajemen Universitas Pamulang dan motivasi yang diberikan berupa kisah Sukses beberapa orang yang sukses dalam berwirausaha secara online dan offine serta diskusi dan Tanya jawab yang dilakukan saat kegiatan berlangsung dapat berguna bagi para pengusaha tempe, tahu, soto, ketoprak dan penjahit Reni Pamulang agar dapat bertahan dalam persaingan dan meningkatkan volume penjualan melalui kolaborasi daring dengan platform online yang tersedia.

Selain pemberian materi dan motivasi, tim PKM juga mengadakan praktek dan simulasi cara dagang secara daring atau online, karena pada saat ini semua lini usaha sudah merambah ke dunia online, sehingga wirausaha konvensional harus selalu siap bersaing dengan wirausaha lainnya yang sudah menguasai pemasaran secara online.

Hasil pengabdian masyarakat yang diperoleh adalah bertambahnya strategi pemasaran baik secara konvensional dan secara online, bertambahnya wawasan akan keilmuan pemasaran, dari cerita cerita sukses pengusaha pengusaha sukses yang mulai dari nol, dan dapat menjalankan usaha dengan bekal ilmu dan wawasan mengenai kewirausahaan yang diberikan, sehingga di masa pandemi Covid-19 ini para pelaku UMKM yang terdiri dari para pedagang di sekitar wilayah Pamulang Barat dapat bersaing dengan para pengusaha dan supermarket dalam memasarkan produk dan jasanya

\section{KESIMPULAN DAN SARAN}

Hasil dari Pelaksanaan kegiatan PKM oleh dosen-dosen Manajemen Fakultas Ekonomi Universitas Pamulang dapat membuahkan hasil yang positif terlihat dari antusias dan bersemangat para pedagang dalam mengikuti pemberian materi, simulasi, diskusi dan tanya jawab, sehingga para pedagang dapat langsung mempraktekkan cara memasarkan melalui media online. 


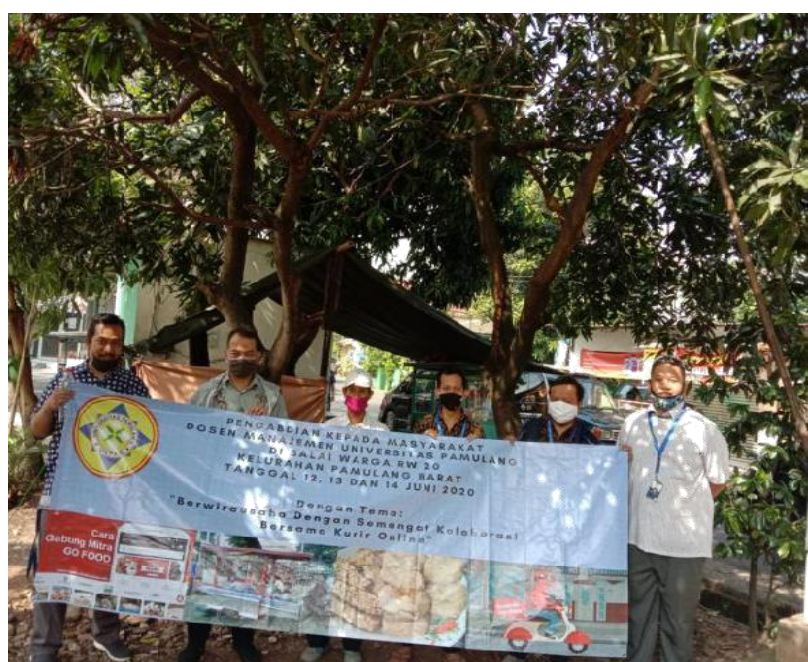

Gambar 2. Hasil PKM Bersama di Lokasi UMKM

Saran kami bagi para pelaku UMKM agar terus konsisten dalam mengevaluasi usaha secara berkala agar dapat berkembang dan bersaing dengan pengusaha lainnya dan diharapkan pengusaha tempe, tahu, soto, ketoprak dan penjahit Reni Jaya terus belajar dari pengalaman wirausaha yang sudah berhasil dalam berwirausaha.

Kami juga berharap kegiatan pengabdian kepada masyarakat di masa yang akan datang dapat lebih terprogram dan terlaksana dengan baik. Semoga kegiatan pengabdian masyarakat ini dapat bermanfaat bagi masyarakat, khususnya para pelaku UMKM di sekitar wilayah Pamulang Barat.

\section{DAFTAR PUSTAKA}

Affandi, A., Sarwani, ., Sobarna, . A., Erlangga, . H., Siagian, . A. O., Purwanto, . A., Effendy, . A. A., Sunarsi, . D., Wicaksono, . W., Suyatin, ., Ariyanti, . E., Wahyitno, ., Manik, . C. D., Juhaeri, . \& Gunartin, . (2020) Optimization of MSMEs Empowerment in Facing Competition in the Global Market during the COVID-19 Pandemic Time. Systematic Reviews in Pharmacy, 11 (11), 1506-1515. doi:10.31838/srp.2020.11.213

Ardiana, I.D.K.R., Brahmayanti, L.A. dan Subaedi. (2010). "Kompetensi SDM UKM dan Pengaruhnya Terhadap Kinerja UKM di Surabaya." Jurnal Manajemen dan Kewirausahaan, 12 (1)

Djamarah, Syaiful Bahri dan Aswan Zain. 2014. "Strategi Belajar Mengajar." Cet 5, PT Rineka Cipta, Jakarta.

Effendy, A. A., Mas'adi, M., Wicaksono, W., Nurhadi, A., \& Murtiyoko, H. (2020).

"Mewujudkan Generasi Muda Yang Unggul Di Era Globalisasi Dengan Berbekal Ilmu Wirausaha Yang Kreatif, Inovatif Dan Diferensiatif Pada Remaja Masjid Al Hikmah Reni Jaya Pamulang Tangerang Selatan.” Jurnal Pengabdian Dharma Laksana, 3(1), 8-15.

Effendy, A. A., Murtiyoko, H., \& Wicaksono, W. (2019). "Pemberian Motivasi Dalam Membangun Genenerasi Muda Yang Berkompeten Dan Religius 
Pada Madrasah Aliyah Ummul Qura Pondok Cabe, Pamulang Tangerang Selatan.” Jurnal Pengabdian Dharma Laksana, 2(1), 1-5

Effendy, A. A., Sudarso, A. P., Nurhadi, A., Arifianto, C. F., \& Kartono, K. (2020). "Peningkatan Profesionalisme Guru Dan Pengembangan SDM Dalam Menghadapi Era Revolusi Industri 4.0 Pada Guru Smk Mulia Buana Parung Panjang Bogor." Abdi Laksana, 1(2).

Erlangga, H. (2018). Spirit Pengembangan Kewirausahaan Di Perguruan Tinggi. Paradigma POLISTAAT: Jurnal Ilmu Sosial dan Ilmu Politik, 1(2), 102-127.

Erlangga, H., Sifatu, . W. O., Wibisono, . D., Siagian, . A. O., Salam, . R., Mas'adi, . M., Gunartin, ., Oktarini, . R., Manik, . C. D., Nani, ., Nurhadi, . A., Sunarsi, . D., Purwanto, . A. \& Kusjono, . G. (2020) Pharmaceutical Business Competition in Indonesia: A Review. Systematic Reviews in Pharmacy, 11 (10), 617-623. doi:10.31838/srp.2020.10.92

Haque, MG., Munawaroh, Sunarsi, D., (2020). Analysis of SMEs Culinary

Marketing Strategy During Covid 19 Pancemic: A Study at "Sate Bebek

Cilegon" Resto in Cilegon, Banten. International Journal of Education, Information Technology, and Others. Vol.3. Issue 2

Lukiastuti, Fitri, et.al (2020). The Influence of Entrepreneur's Personal Characteristics on SMES Performance Mediated by Entrepreneurial Orientation. International Journal of Psychosocial Rehabilitation. Volume 24 - Issue 8

Maddinsyah, A., Sunarsi, D., Hermawati, R., Pranoto. (2020). Analysis of location selection effect on the user decision that influcence the success of the service business of micro, small and medium enterprise (MSME) in bandung timur region. International Journal of Advanced Science and Technology. Vol. 29 No. 06

Nurhayati, N. I. D. N., Hindarsah, I., Sos, S., Erlangga, H., Sos, S., \& Maun Jamaludin, I. (2018). Pelatihan Pembukuan Di UKM Sumpia Chantika Dewi Cimindi Cimahi. Laporan Program Kepakaran Fisip Unpas Pengabdian Kepada Masyarakat Tahun Akademik 2016/2017, 1-22.

Sunarsi, D. (2018). "Analisis Motivasi Kerja Tenaga Pendidik Sukarela Pada Pusat Kegiatan Belajar Masyarakat (PKBM) Bimasda Kota Tangerang Selatan”. Kreatif: Jurnal Ilmiah Prodi Manajemen Universitas Pamulang, 6(2), 53-65. Sunarsi, D., \& Asmalah, L. (2018). "Pelatihan Manajemen Pengembangan Diri Bagi Penerima Beasiswa RZIS UGM Dan Dompet Shalahuddin Jogjakarta". Jurnal Pengabdian Dharma Laksana, 1(1).

Vivathuvahna, A.A. dan Nugroho, T.R.D.A. (2015). "Intensi Kewirausahaan Mahasiswa Universitas Trunojoyo Madura.” Jurnal Agriekonomika, 4 (1). 